\title{
Focus-group interview and data analysis
}

\author{
Fatemeh Rabiee \\ School of Health and Policy Studies, University of Central England, Birmingham B42 2SU, UK
}

\begin{abstract}
In recent years focus-group interviews, as a means of qualitative data collection, have gained popularity amongst professionals within the health and social care arena. Despite this popularity, analysing qualitative data, particularly focus-group interviews, poses a challenge to most practitioner researchers. The present paper responds to the needs expressed by public health nutritionists, community dietitians and health development specialists following two training sessions organised collaboratively by the Health Development Agency, the Nutrition Society and the British Dietetic Association in 2003. The focus of the present paper is on the concepts and application of framework analysis, especially the use of Krueger's framework. It provides some practical steps for the analysis of individual data, as well as focus-group data using examples from the author's own research, in such a way as to assist the newcomer to qualitative research to engage with the methodology. Thus, it complements the papers by Draper (2004) and Fade (2004) that discuss in detail the complementary role of qualitative data in researching human behaviours, feelings and attitudes. Draper (2004) has provided theoretical and philosophical bases for qualitative data analysis. Fade (2004) has described interpretative phenomenology analysis as a method of analysing individual interview data. The present paper, using framework analysis concentrating on focus-group interviews, provides another approach to qualitative data analysis.
\end{abstract}

Focus-group interviews: Qualitative data analysis

Focus-group interviews are becoming increasingly popular in health research for exploring what individuals believe or feel as well as why they behave in the way they do. They offer a useful vehicle for involving users in care management and strategy development, needs assessment, participatory planning and evaluation of health promotion and nutrition intervention programmes (Basch, 1987; Gregory, 1991; Duke et al. 1994; Kitzinger, 1995; Higingbottom, 1998; Richardson \& Rabiee, 2001; Van Dillen et al. 2003). The main aim is to understand, and explain, the meanings, beliefs and cultures that influence the feelings, attitudes and behaviours of individuals. It is ideally suited for exploring the complexity surrounding food choice and dietary and other lifestyle behaviours within the context of lived experience, and in ways encourage the participants to engage positively with the process of the research. Drawing on relevant literature as well as personal experience, the first section of the present paper describes some of the commonly-asked questions about the use of focus-group interviews in health research and the issues that need to be considered before and during this method of data collection. The second section provides a detailed and practical account of Krueger's (1994) framework of data analysis. Krueger's (1994) framework analysis has been chosen because personal experience has indicated that the approaches are easily accessible to both researchers and students, and that it is one of the most useful starting points for analysing focus-group interviews.

\section{What is a focus-group interview?}

A focus group is, according to Lederman (see Thomas et al. 1995), 'a technique involving the use of in-depth group interviews in which participants are selected because they are a purposive, although not necessarily representative, sampling of a specific population, this group being 'focused' on a given topic'. Participants in this type of research are, therefore, selected on the criteria that they would have something to say on the topic, are within the age-range, have similar socio-characteristics and would be comfortable talking to the interviewer and each other (Richardson \& Rabiee, 2001). This approach to selection relates to the concept of 'Applicability', in which subjects

Corresponding author: Professor Fatemeh Rabiee, fax +44 121331 5498, email Fatemeh.Rabiee@uce.ac.uk 
are selected because of their knowledge of the study area (Burrows \& Kendall, 1997). One of the distinct features of focus-group interviews is its group dynamics, hence the type and range of data generated through the social interaction of the group are often deeper and richer than those obtained from one-to-one interviews (see Thomas et al. 1995).

Focus groups could provide information about a range of ideas and feelings that individuals have about certain issues, as well as illuminating the differences in perspective between groups of individuals. For example, using focus-group interviews diverse views about health and issues affecting health amongst professionals and the members of the public working and living in an outercity deprived area of Birmingham have been generated. In this research the data derived from the community (young people, single-parent young women and professional women living in the area) are distinct and yet cover a range of issues affecting the health of the participants. The narratives generated from professionals working in this area, although very different, complement the range of issues raised by the public (Rabiee, 1999). Focus groups can generate large amounts of data in a relatively short time span, and the findings may be used to precede quantitative procedures. Like one-to-one interviews, the results of focus-group interviews can be presented in uncomplicated ways using lay terminology supported by quotations from the participants. Krueger \& Casey (2000), while describing in detail the advantages and disadvantages of focus groups, point out when to use focus-group interviews and when not to use them.

The uniqueness of a focus group is its ability to generate data based on the synergy of the group interaction (Green et al. 2003). The members of the group should, therefore, feel comfortable with each other and engage in discussion. Krueger \& Casey (2000) point out that for some individuals self-disclosure is natural and comfortable, while for others it requires trust and effort. It is for this reason that they recommend investing time and effort in selecting members of the group. Krueger (1994) believes rich data can only be generated if individuals in the group are prepared to engage fully in the discussion and, for this reason, advocates the use of a homogenous group. Based on the topic under investigation Krueger (1994) suggests that participants should share similar characteristics: gender group, age-range, ethnic and social class background. Most researchers, although they would not disagree with the concept of homogeneity, recommend that participants should not know each other, thus encouraging more honest and spontaneous expression of views and a wider range of responses It also prevents set behaviours relating to pre-existing relationships and patterns of leadership in the group (see Thomas et al. 1995). Kitzinger (1994), on the other hand, advocates the use of pre-existing groups, as acquaintances could relate to each other's comments and may be more able to challenge one another. Personal experience indicates that when exploring very sensitive and personal issues the use of pre-existing groups might be advantageous, as there is already an extent of trust amongst the members of the group, which will encourage the expression of views. This factor is particularly important when very little information is available on the topic under investigation and the data from exploratory focus-group interviews is to be used to formulate and design a large-scale study. For example, in a study widening participation and increasing access to higher education amongst Muslim women (Rabiee \& Thompson, 2000) found there was clear benefit from preexisting acquaintance. The women who all knew each other, felt comfortable talking about a number of very personal issues that affected their participation, and were able to express their views on how to widen participation.

Regardless of whether a pre-existing or newly-formed group is used, the important role of the group facilitator or moderator should not be underestimated (Krueger, 1994; Burrows \& Kendall, 1997). A skilful moderator, as well as being able to manage the existing relationship, could create an environment in which the participants who do not know each other feel relaxed and encouraged to engage and exchange feelings, views and ideas about an issue. Apart from the facilitator or moderator a note taker should be present to observe non-verbal interactions, indicate the impact of the group dynamic, document exchanges of views and the general content of discussion and note which statement is made by which particular individual, thereby supplementing the oral text and enabling a fuller analysis of the data (Kitzinger, 1994, 1995).

Another frequently-asked question is about the number of focus groups. Krueger (1994) suggests continuing with running focus groups until a clear pattern emerges and subsequent groups produce only repetitious information (theoretical saturation). However, several authors, including Krueger (1994), suggest that for a simple research question the number of focus groups necessary may only be three or four (for a full discussion of this issue, see Burrows \& Kendall, 1997).

The optimum number of participants for a focus group may vary. Krueger \& Casey (2000) suggest between six and eight participants, as smaller groups show greater potential. However, the number generally suggested as being manageable is between six and ten participants; large enough to gain a variety of perspectives and small enough not to become disorderly or fragmented. Recruiting participants for a focus-group interview is a big challenge, particularly if the informants belong to low-income or minority ethnic groups. Experience of researching these groups suggests that lack of confidence and low selfesteem often prevent these individuals participating in a group discussion. Focus-group interviews could, therefore, be used as a vehicle to empower the participants from these communities. Another potential problem in using focus groups is the number of non-attenders. The recommendation is, therefore, to over-recruit by 10-25\%, based on the topic and groups of participants. In order to maximise participation it is important to obtain an agreed date from the informants well in advance of the interviews and to remind them a few days before they start.

Each group interview usually lasts approximately $1-2 \mathrm{~h}$, based on the complexity of the topic under investigation, number of questions and the number of participants. It is, therefore, ethical and good practice to warn the participants about their time commitment. 


\section{Data analysis}

Qualitative research and, in particular, focus-group interviews generate large amounts of data, which tend to overwhelm novice as well as experienced researchers. A $1 \mathrm{~h}$ interview could easily take 5-6h to transcribe in full, leading to thirty to forty pages of transcripts. Thus, a central aim of data analysis, according to Robson (1993), is to reduce data. Yin (1989) points out that data analysis consists of a number of stages, i.e. examining, categorising and tabulating or otherwise recombining the evidence, in order to address the initial goal of a study. Krueger \& Casey (2000) build on this concept and suggest that the purpose should drive the analysis; they believe that 'analysis begins by going back to the intention of the study and survival requires a clear fix on the purpose of the study'. Following this concept, although hard at times, is extremely helpful for managing the data, making sense of what is going on, getting rid of extra and irrelevant information and travelling safely through the maze of large and complicated paths of information.

The process of qualitative analysis aims to bring meaning to a situation rather than the search for truth focused on by quantitative research. Strauss \& Corbin (1998) describe analysis as '... the interplay between researchers and data', acknowledging that there is an extent of subjective selection and interpretation of the generated data. It is important to acknowledge that regardless of the type of research (qualitative or quantitative) an extent of subjectivity exits. The distinction should be seen more in relation to the stage of the process rather than just the type of subjectivity. For example, the issue of subjectivity in surveys is often at the stage of designing the questionnaire, the pre-set answers at this stage could prevent the expression of other potential answers; hence, indicating an extent of selective answers and interpretations of the issue under investigation.

Having made this point, in order to minimise the potential bias introduced in analysing and interpreting focus group data Krueger \& Casey (2000) point out that the analysis should be systematic, sequential, verifiable, and continuous. Following this path provides a trail of evidence, as well as increasing the extent of dependability, consistency and conformability (Lincoln \& Guba, 1989) of the data, important issues for assessing the quality of qualitative data (Secker et al. 1995).

The first step in establishing a trail of evidence is a clear procedure of data analysis, so that the process is clearly documented and understood. This step would allow another researcher to verify the findings; it safeguards against selective perception and increases the rigour of the study. In order to achieve this objective, there must be sufficient data to constitute a trail of evidence.

Although the main source of data analysis is the recorded spoken language derived from the interview; nevertheless, reflection about the interview, the settings and capturing the non-verbal communication expressed by the member of the groups would add a valuable dimension to the construction and analysis of data. This record could be in the form of an audiotape or a videotape. It is recommended that a reflective diary should be kept by the facilitator or moderator and that observational notes should be written immediately after each focus-group interview.

\section{Approaches to data analysis}

There are a number of approaches to the analysis of qualitative data. In practice, as Green \& Thorogood (2004) identified, most researchers use a combination of approaches. The present paper describes Krueger's (1994) framework analysis, but also incorporates some key stages of 'framework analysis' described by Ritchie \& Spencer (1994). The advantage of the Krueger (1994) approach is that it provides a clear series of steps, which could help first-time researchers to manage the large amount and complex nature of qualitative data much more easily. 'Framework analysis' is used for both individual and focus-group interviews.

Unlike quantitative analysis, qualitative analysis, particularly focus-group analysis, occurs concurrently with data collection. Krueger (1994) suggests that a helpful way of thinking about this role is to consider a continuum of analysis ranging from the mere accumulation of raw data to the interpretation of data:

the analysis continuum:

raw data; descriptive statements; interpretation.

It is important to point out that analysis does not take place in a linear form and that one part of the process overlaps another. 'Framework analysis' as described by Ritchie \& Spencer (1994), is 'an analytical process which involves a number of distinct though highly interconnected stages'. The five key stages outlined are: familiarization; identifying a thematic framework; indexing; charting; mapping and interpretation. The other distinctive aspect of framework analysis is that although it uses a thematic approach, it allows themes to develop both from the research questions and from the narratives of research participants.

The process of data analysis begins during the data collection, by skilfully facilitating the discussion and generating rich data from the interview, complementing them with the observational notes and typing the recorded information. This stage is followed by familiarisation with the data, which can be achieved by listening to tapes, reading the transcripts in their entirety several times and reading the observational notes taken during interview and summary notes written immediately after the interview. The aim is to immerse in the details and get a sense of the interview as a whole before breaking it into parts. During this process the major themes begin to emerge.

The next stage involves identifying a thematic framework, by writing memos in the margin of the text in the form of short phrases, ideas or concepts arising from the texts and beginning to develop categories At this stage descriptive statements are formed and an analysis is carried out on the data under the questioning route.

The third stage, indexing, comprises sifting the data, highlighting and sorting out quotes and making comparisons both within and between cases. The fourth stage, charting, involves lifting the quotes from their original context and re-arranging them under the newly-developed 
Table 1. Text transcribed during the process of developing and writing up a policy for mainstream Children's Services: indexing and charting stage

\begin{tabular}{ll}
\hline Line no. & \multicolumn{1}{c}{ Transcription } \\
\hline 164 & In that they thought it was positive and it actually moved \\
165 & forward, yes I think so, with some of the feedback yes, yes, I \\
166 & think so, because that's I think links into the next about the \\
167 & planning mainstream service, because all the time in terms of \\
168 & developing you know, a policy and a strategy, what was also \\
169 & firmly in my mind was well how do we make this happen, \\
170 & because I detest policies that just look good on paper, and you \\
171 & cant operationalise because the having a policy for me is, it's a \\
172 & statement of this is what we are trying to do, and you \\
173 & operationalise it by saying, and this is how we do things around \\
174 & this place. So at the core l'm very sort of practical being, I like to \\
175 & know how things are going to work because that fits into one of \\
176 & my key drivers I think for me as a person and why I do the job I \\
177 & do, which is actually about making a difference for kids, \\
178 &
\end{tabular}

${ }^{*}$ Codes relate to highlighted text.

appropriate thematic content. Table 1 gives an example of indexing and charting from a transcribed text.

Indexing and charting could also be viewed as managing the data. One of the most important aspects of this task is data reduction, which is achieved by comparing and contrasting data and cutting and pasting similar quotes together. In order to manage this stage successfully Krueger (1994) suggests the following practical steps.

\section{Practical steps for managing and sorting out data}

Krueger \& Casey (2000) advocate the use of either a long table or a computer-based approach for cutting, pasting, sorting, arranging and rearranging data through comparing and contrasting the relevant information. Although there is specialised software such as QSR NUT*IST (Richards, 1998), it is possible to analyse the transcripts using Microsoft Word, or indeed 'by hand'.

The procedure for the 'long table' approach requires having access to either a long table or a room with lots of floor or wall space. Before cutting the transcripts apart, it is important to:

a) number each line of each transcript;

b) make two hard copies of each transcript; one to cut up and one that stays intact;

c) print transcripts on different coloured paper, e.g. 'professionals' green, 'young people' blue,' single parents' yellow, 'working mums' pink;

d) arrange the working transcript in a reasonable order, i.e. sequence in which the interview took place, categories of participants: age, young people; social group, low-income families or professionals; gender, male or female;

e) have enough pages of flipchart or newsprint. Place the pages on the long table, on the floor or on the wall. Write on each page one of the focus group questions to be analysed. It may also be necessary to divide the pages of newsprint or flipchart into sections to represent different groups of participants, i.e. young people, single parents, professionals.

Having prepared for this stage, Krueger \& Casey (2000) suggest that the researcher should read each quote and answer these four questions:

1. did the participant answer the question that was asked? If yes, go to question 3; if no, go to question 2 ; if don't know, set it aside and review it later;

2. does the comment answer a different question in the focus group? If yes, move it to the appropriate question; if no, go to question 3;

3. does the comment say something of importance about the topic? If yes, put it under the appropriate question; if no, set it aside;

4. is it something that has been said earlier? If yes, start grouping like quotes together; if no, start a separate pile.

Having gone through this systematic process, soon the newsprint pages are filled up with relevant quotes. For the time being, leave those 'not so relevant' quotes that have been set aside, it may be necessary to go back to those quotes at a later stage.

\section{Interpretation of data}

The data are now ready for the final stage of analysis, i.e. mapping and interpreting. One of the tasks here is not only to make sense of the individual quotes, but also to be imaginative and analytical enough to see the relationship between the quotes, and the links between the data as a whole. Krueger (1994) provides seven established criteria, which suggest the following headings as a framework for interpreting coded data: words; context; internal consistency; frequency and extensiveness of comments; specificity of comments; intensity of comments; big ideas.

The following extracts taken from a piece of research on experience of heart attack provides an example of how to 
apply these headings to the data:

JF: 'I didn't think I was having a heart attack because it was my arm.'

DS: 'But certainly before I had a heart attack, I thought Oh my God a heart attack that would be horrendous, you know but having one well I don't know, I really didn't feel anything. I wasn't in a great deal of pain.' EM: 'And they kept saying have you got pain and I said no and they said you must have pain. I said but I haven't. You haven't got it in your arm or your chest. I said no.'

JG: 'Well with the trauma of my father dying a week after I came out of hospital and the problems we have had has made it a difficult time. I have found it more stressful.'

KZ: 'I don't believe I've had a heart attack, I still find it very difficult to understand, but the tests showed I did so that's it.'

$\mathrm{KN}$ : 'Well, what is difficult about it because it's what a lot of people say.'

KZ: 'Well, perhaps it's because my visions or ideas of a heart attack were that I would be suffering more pain and I didn't. Was it possible I had a heart attack a year ago and not know it?'

\section{Consider the actual words used and their meaning}

When the participants talk about the term 'heart attack' it becomes evident that their actual experience shows little relationship with their understanding of the term before the event. There seems to be a belief that a heart attack involves a lot more suffering than they had experienced, so coming to terms with what had happened to them involves re-defining this key term.

\section{Consider the context}

The wording of the moderators' questions and subsequent comments made by others in the group influences the context within which the comments are made.

The respondents are never asked directly to talk about the actual experience of having a heart attack, although when the conversation gets round to talking about how they feel now and what they think about the future, it seems that they need to recount their experience. They also talk about previous occasions when similar things happened to them.

\section{Consider the frequency and extensiveness of comments}

Frequency relates to consideration of how often a comment or view is made, while having enough insight to 'spot a gem' when it comes along. The term extensive refers to the number of participants who express a particular view.

All participants talk at length about their experience apart from JG, who had lost his father since coming out of hospital so had things on his mind other than his own state of health. They are simply telling the story again, and it seems that this process is about coming to terms with what had happened to them. Along with the actual heart attack experiences, the patients talk about previous times when they had felt unwell and they attempt to make sense of them in light of their recent diagnosis.

KZ: 'Was it possible I had a heart attack a year ago and not know it?'

\section{Intensity of the comments}

Consider the depth of feeling in which comments or feelings are expressed; the following are some examples of 'how people feel now'. Women used more negative terms to describe their current state of health. There is some variation in the ex-patients comments about how they are feeling now. All the men describe their current state of health quite positively, whereas several of the women use more negative terms.

MG: 'It has been a very depressing couple of weeks, thinking when am I going to be all right, you know. What can I do, how far can I go.'

JF: 'I get very depressed. Sometimes I sit and cry. I couldn't really tell you what I am crying for. I mean its just I feel a bit low in myself towards the end of the day sort of thing. It only lasts a little while.'

MH: 'Reasonable, but scared. It's really lonely and then I get depressed. I've got no-one to talk to.'

\section{Internal consistency}

Consider any changes in opinion or position by the participants. For example, the following quotes about children in primary school clearly indicate some changes in participant's views and an extent of consensus:

Teacher A: 'Children in my class are always tired, can't focus on anything more than five minutes.'

Playgroup leader: 'You are right, most of them come to school without having a breakfast, what do you expect?' Teacher B: 'A clear lack of parenting skills, they do not send the children to bed early enough, do they?'

Playgroup assistant: 'Haven't we been a bit judgemental? There are some people including myself who don't like eating anything first thing in the morning.'

Teacher B: 'Good point, my husband never eats breakfast during weekdays, and he can't stop eating on Saturday, as he gets up around 10.'

\section{Specificity of responses}

Greater attention is placed on responses referring to personal experience as opposed to hypothetical situations. For example, JG's reference to his father's death gives a specific and related answer.

\section{Big ideas}

Consider larger trends or concepts that emerge from an accumulation of evidence and cut across the various discussions. Krueger (1994) suggests taking a break for a few days at this stage in order to refocus on the big picture.

\section{Development of the framework}

These criteria are reduced to the following five headings in a later publication (Krueger \& Casey, 2000): frequency; 
Table 2. Headings to help in the interpretation of focus group data

\begin{tabular}{|c|c|c|}
\hline Krueger (1994) & $\begin{array}{l}\text { Krueger \& Casey } \\
(2000)\end{array}$ & $\begin{array}{l}\text { F Rabiee } \\
\text { recommendation }\end{array}$ \\
\hline 1. Words & & 1. Words \\
\hline 2. Context & & 2. Context \\
\hline $\begin{array}{l}\text { 3. Internal } \\
\text { consistency }\end{array}$ & & $\begin{array}{l}\text { 3. Internal } \\
\text { consistency }\end{array}$ \\
\hline $\begin{array}{l}\text { 4. Frequency and } \\
\text { extensiveness }\end{array}$ & 1. Frequency & 4. Frequency \\
\hline $\begin{array}{l}\text { 5. Intensity } \\
\text { of comments }\end{array}$ & 2. Motion & $\begin{array}{l}\text { 5. Intensity } \\
\text { of comments }\end{array}$ \\
\hline \multirow[t]{2}{*}{$\begin{array}{l}\text { 6. Specificity of } \\
\text { responses }\end{array}$} & $\begin{array}{l}\text { 3. Specificity of } \\
\text { responses }\end{array}$ & $\begin{array}{l}\text { 6. Specificity of } \\
\text { responses }\end{array}$ \\
\hline & 4. Extensiveness & 7. Extensiveness \\
\hline 7. Big ideas & 5. Big picture & 8. Big picture \\
\hline
\end{tabular}

specificity; emotions; extensiveness; big picture. The main difference is that words, context and internal consistency have been excluded from the interpretation, frequency and extensiveness have been separated into two separate categories, intensity of comments and big ideas have been reframed as emotions, and the big picture has been introduced. Although the development of the new categories is welcome, as it is now crisp and concise, experience suggests that students and the first-time practitioner researcher tend to find that incorporating the three excluded criteria is easier to follow, it can be applied with more rigour and produce a richer interpretation. A modification to the latest criteria is recommended that includes the concepts of word, context and internal consistency; therefore, making eight criteria rather than five (see Table 2).

\section{Conclusion}

The present paper discusses the role of focus-group interviews in health and nutrition research. An attempt has also been made to answer some of the questions most frequently asked by students and practitioner researchers. Some practical guidance is provided for the analysis of focus-group interviews, using Krueger (1994) and Ritchie \& Spencer (1994) framework analyses. The analysis of qualitative data requires the development of new skills, but also imagination, patience, time and practice. Developing this skill is a good investment and the rewards are numerous!

\section{Acknowledgements}

I would like to thank my colleagues Dr Jackie Landman, Mrs Stephanie Fade and Dr Liza Draper for their useful comments and reading this paper. Also, special thanks go to my ex-students, Christine Richardson, Karen Noy and Anne-Marie Morris, who, with their dedication and enthusiasm for learning, enabled me to further my experience of applying Krueger's framework and add to the current knowledge on qualitative data analysis.

\section{References}

Basch C (1987) Focus group interview: an under-utilised research technique for improving theory and practice in health education. Health Education Quarterly 14, 411-418.
Burrows D \& Kendall S (1997) Focus groups: What are they and how can they be used in nursing and health care research? Social Sciences in Health 3, 244-253.

Draper AK (2004) The principles and application of qualitative research. Proceedings of the Nutrition Society $\mathbf{6 3}$ 641-646.

Duke SS, Gordon-Sosby K, Reynolds KD \& Gram IT (1994) A study of breast cancer detection practices and beliefs in black women attending public health clinics. Health Education Research 9, 331-342.

Fade S (2004) Using interpretative phenomenological analysis for public health nutrition and dietetic research: a practical guide. Proceedings of the Nutrition Society 63, 647-653.

Green J \& Thorogood N (2004) Qualitative Methods in Health Research. London: Sage Publications.

Green JM, Draper AK \& Dowler EA (2003) Short cuts to safety: risk and 'rules of thumb' in accounts of food choice. Health Risk and Society 5, 33-52.

Gregory S \& McKie L (1991) The smear test: listening to women's views. Nursing Standard 5, 32-36.

Higingbottom G (1998) Focus groups: their use in Health Promotion research. Community Practitioner 72, 360-363.

Kitzinger J (1994) The methodology of focus groups: the importance of interactions between research participants. Sociology of Health and Illness 16, 103-121.

Kitzinger J (1995) Qualitative research: introducing focus groups. British Medical Journal 311, 299-302.

Krueger RA (1994) Focus Groups: A Practical Guide for Applied Research. Thousand Oaks, CA: Sage Publications.

Krueger RA \& Casey MA (2000) Focus Groups: A Practical Guide for Applied Research, 3rd ed. Thousand Oaks, CA: Sage Publications.

Lincoln Y \& Guba E (1989) Fourth Generation Evaluation. Newbury Park, CA: Sage Publications.

Rabiee F (1999) Evidence based practice: its relevance to nutritional intervention programmes. Proceedings of Nutrition Society 58, 50A.

Rabiee F \& Thompson D (2000) Widening ParticipationIncreasing Access to Higher Education for Muslim Women. Birmingham: University of Central England and Birmingham University.

Richards L (1998) Qualitative Solution and Research (QSR) NUT*IST Introductory Handbook. Melbourne, Australia: QSR.

Richardson CA \& Rabiee F (2001) 'A Question of Access' - an exploration of the factors influencing the health of young males aged 15-19 living in Corby and their use of health care services. Health Education Journal 60, 3-6.

Ritchie J \& Spencer L (1994) Qualitative data analysis for applied policy research. In Analysing Qualitative Data, pp. 173-194 [A Bryman and RG Burgess, editors]. London: Routledge.

Robson C (1993) The Real World Research-A Resource for Social Scientists and Practitioner-researchers. Oxford: Blackwell Publications.

Secker J, Wimbush E, Watson J \& Milburn K (1995) Qualitative methods in health promotion research: some criteria for quality. Health Education Journal 54, 74-87.

Strauss A \& Corbin J (1998) Basics of Qualitative Research, Techniques and Procedures for Developing Grounded Theory, 2nd ed. Thousand Oaks, CA: Sage Publications.

Thomas L, MacMillan J, McColl E, Hale C \& Bond S (1995) Comparison of focus group and individual interview methodology in examining patient satisfaction with nursing care. Social Sciences in Health 1, 206-219.

Yin RK (1989) Case Study Research: Design and Methods, 2nd ed. London: Sage Publications. 